\title{
modelo de gestão pública por resultados em Minas Gerais analisado à luz da experiência do Programa Estado para Resultados
}

\author{
Cinthia Helena de Oliveira Bechelaine, \\ Mauro César da Silveira e Camila Barbosa Neves
}

\section{Introdução}

A ascensão de teorias críticas às burocracias, classificadas como ineficientes e apegadas à norma, buscou a redução do déficit e a diminuição do setor estatal, bem como a implantação do modelo gerencial marcado pela influência da iniciativa privada. Desde então, a ideia de uma gestão por resultados tem dominado a agenda de reformas governamentais.

No Estado de Minas Gerais, a partir de 2003, foi instituído o programa Choque de Gestão, cujas premissas abordam o ajuste fiscal e a modernização da administração pública. Durante os primeiros quatro anos dessa gestão, foram estabelecidos arranjos institucionais como a integração plano-orçamento, o escritório central de projetos, os acordos de resultados e as avaliações de desempenho.

O Programa Estado para Resultados (EpR), marca da segunda geração de políticas do Choque de Gestão mineiro, propõe um modelo de gestão pública por resultados a partir de mecanismos criados para acompanhar resultados, além 
de auxiliar o processo de tomada de decisões na administração. É estabelecido como uma estrutura provisória, extinguindo-se em 31 de janeiro de 2011, cuja coordenação era de responsabilidade do vice-governador do estado, em parceria com a Secretaria de Estado de Planejamento e Gestão (Seplag). O programa era composto por três unidades não formais, sendo elas: Unidade de Gestão Estratégica, Unidade de Empreendedores e Unidade de Indicadores.

Em síntese, o artigo busca compreender como se articulam as funções e as estruturas no modelo de gestão por resultados mineiro. Procura-se, também, evidenciar a composição do EpR a partir de seu processo de construção, modelos teóricos utilizados e estrutura de funcionamento.

Para cumprir esse objetivo, optou-se pela pesquisa descritiva longitudinal, que permite, segundo Hair Jr, Babin, Money e Samouel (2005), mapear elementos administrativos de modo que suas tendências sejam observadas cronologicamente. Como método de pesquisa, utilizou-se a grounded theory, traduzida por "teoria fundamentada nos dados" e apresentada como uma alternativa atraente para pesquisas qualitativas sobre fenômenos organizacionais (Bandeira-De-Mello; Cunha, 2006). O método originou-se do trabalho de Glaser e Strauss (1967), e emerge da análise de dados e do desenvolvimento, de forma progressiva, de hipóteses fundamentadas nesses dados. Ao contrário de outros métodos, a grounded theory não se inicia com uma teoria preconcebida (hipótese).

Para obter uma compreensão mais detalhada da realidade e situação dos envolvidos no estudo de caso do EpR, foram consultados documentos internos, artigos escritos sobre a experiência e, principalmente, entrevistas semiestruturadas realizadas com os coordenadores do programa, bem como os responsáveis pelas três unidades que o compõem. O software ATLAS-ti foi utilizado na pesquisa para apoio às interpretações das entrevistas e organização documental. O software foi criado, principalmente, visando à construção de teorias (BANDEIRA-DEMello; Cunha, 2003), sendo, portanto, uma alternativa importante para o desenvolvimento da grounded theory.

De forma esquemática, o trabalho está organizado em quatro seções principais. A segunda seção apresenta, sinteticamente, a trajetória das reformas gerencias na administração pública, desde a crítica ao modelo burocrático até o advento da gestão pública por resultados. Com vistas a ilustrar e problematizar a elaboração teórica, a terceira seção apresenta o estudo de caso do EpR. Trata-se, portanto, de uma análise da concepção, evolução e validade do programa a partir da percepção de seus dirigentes. $\mathrm{Na}$ última seção, destinada às considerações finais, cabe a constatação de que Minas Gerais apresenta um modelo de gestão por resultados marcado pelo incrementalismo, e efetivado, em parte, pela experiência do EpR.

\section{A gestão pública por resultados}

O termo "Gestão por resultados" advém da "Administração por objetivos" (APO), mencionado pela primeira vez por Peter Drucker em 1954, no livro The practice of management (Serra, 2008), e é definido como um sistema que relaciona metas organizacionais com o desenvolvimento da empresa. Nessa concepção, os objetivos proporcionam um senso de direção para a organização, guiam as decisões e servem de parâmetros para avaliação de desempenho.

Da administração por objetivos de Drucker, para a gestão por resultados da 
administração pública atual, foi necessário um longo percurso que teve início junto ao processo de se repensar o papel do Estado, otimizar seu desempenho, melhorar sua eficiência e a qualidade dos serviços, ideias consolidadas no final do século 20.

O movimento gerencialista e a cultura do management foram transportados do setor privado para o setor público, engendrando o movimento "reinventando o governo" concebido pelo trabalho de David Osboren e Ted Gaebler. Os autores argumentam a favor de um governo empreendedor, caracterizado pelo estímulo à competição, pela transferência de controle aos cidadãos e pela focalização nos resultados - orientando-se pela missão e objetivos, em vez de regras e regulamentos (Osborne; GAEBLER, 1995).

Por "resultados" entende-se a mudança desencadeada na realidade pelo produto final (SERRA, 2008). Esse significado referese, também, ao conceito de efeitos (outcomes): aquilo que uma intervenção alcançará ou alcançou no curto e no médio prazo (OcDE, 2002).

Por produtos, também conhecidos como outputs, entende-se "bens, equipamentos ou serviços que resultam da intervenção de desenvolvimento" (OCDE, 2002). Assim, exemplos de produtos podem ser rodovias pavimentadas, escolas construídas, postos de saúde implantados, entre outros. Entretanto, os produtos gerados pelas intervenções podem, ou não, conduzir a resultados/efeitos. Por exemplo, um maior número de rodovias pavimentadas pode não resultar na ampliação do dinamismo econômico da região.

Com o intuito de gerenciar esses produtos, de acordo com o glossário dos Principais Termos da Avaliação e da Gestão Centrada nos Resultados (OcDE, 2002), a gestão por resultados compreende uma estratégia de gestão orientada para o desempenho, a obtenção de resultados e efeitos, ao contrário de produtos. De forma semelhante, para Serra (2008), a gestão por resultados se apresenta como uma proposta de cultura organizadora de gestão, mediante a qual se põe ênfase nos resultados e não nos processos e procedimentos.

Complementando a definição de gestão por resultados, o glossário relaciona a gestão com a inclusão de elementos estratégicos,

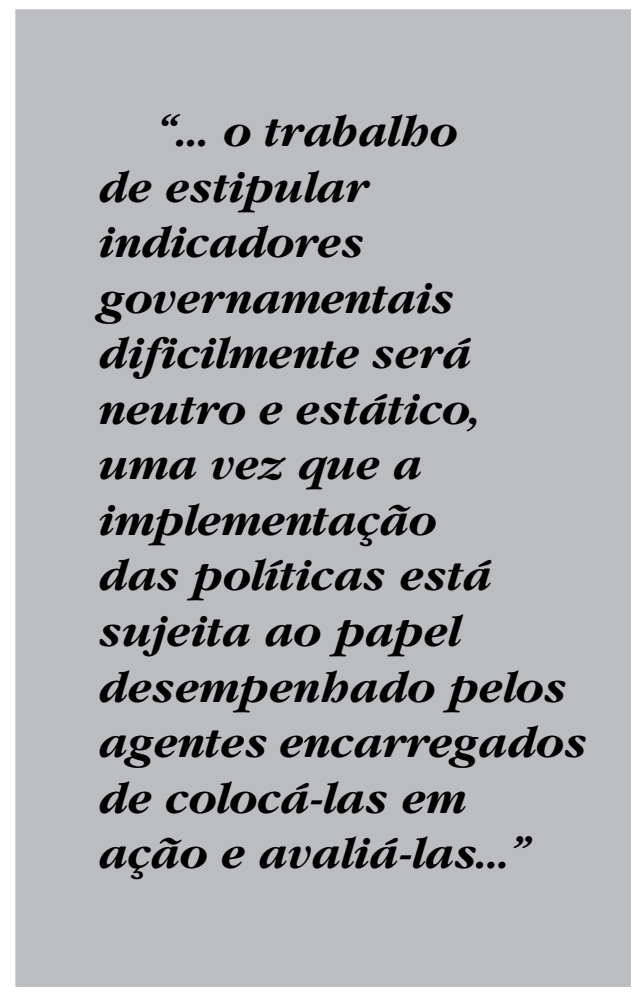

como o estabelecimento de objetivos, metas e indicadores de desempenho (OCDE, 2002). Os indicadores de desempenho, no campo aplicado das políticas públicas, são medidas usadas para permitir o monitoramento das condições de vida e bem-estar da população por parte do poder público e da sociedade civil, e subsidiar a investigação acadêmica sobre a demanda social e as atividades de 
planejamento público na formulação de políticas, nas diferentes esferas de governo (JANUZZI, 2005).

Como coloca Corrêa (2007), a gestão pública por resultados foi desenvolvida como uma estratégia que tem início no momento do planejamento e vai até o processo de feedback das políticas públicas, podendo ser considerada uma prática de desenvolvimento institucional, respeitando princípios da distribuição eficiente de recursos públicos e prestação de contas à sociedade, como observa a autora:

Alcançar uma boa prática de gestão pública por resultados não implica somente a implementação de mecanismos de avaliação institucional. A gestão pública por resultados é viabilizada por diversos mecanismos gerenciais, começando pelo planejamento das ações governamentais sejam elas organizadas em projetos ou programas; ampliação da flexibilidade gerencial; desenvolvimento de indicadores de desempenho; e, por fim, a avaliação de desempenho, que, além da medição das metas estabelecidas, fornece subsídios para retroalimentação de informações para o desenvolvimento de futuras metas gerenciais. (CORRÊA, 2007, p. 498)

Finalmente, cabe ressaltar que o modelo de gestão por resultados preocupa-se com o processo que assegure a criação de valor público dentro de um regime democrático. Por valor público entendem-se respostas efetivas às demandas politicamente desejáveis, com prioridade coletiva e que requeiram mudanças sociais (resultados) que modifiquem certos aspectos no conjunto da sociedade (Moore, 1995). Assim, a gestão por resultados foca o cidadão, por meio de objetivos governamentais, e orienta a mudança social.

Como sintetiza Serra (2008), o objetivo último da gestão pública por resultados "é gerar capacidade nas suas organizações para que consigam, mediante a gestão do processo de criação de valor público, os resultados estipulados nos objetivos do programa de governo" (SERRA, 2008, p. 32).

\section{Programa Estado para Resul- tados, um estudo de caso}

Como indicado no estudo "Minas Gerais do século XXI", em 2003, o Estado de Minas Gerais atravessava um contexto de agravamento do quadro fiscal e graves problemas de desempenho da administração pública (Vilhena, 2006). Em decorrência desse quadro, buscou-se, a partir do programa Choque de Gestão, uma resposta à crise fiscal e administrativa, num esforço de alcançar o equilíbrio das contas públicas e modernizar o aparato institucional do estado.

Como instrumento de planejamento de longo prazo, foi aprovado pela Assembleia Legislativa de Minas Gerais (ALMG) o Plano Mineiro de Desenvolvimento Integrado (PMDI), apresentando-se como o plano estratégico norteador da ação governamental do Estado de Minas Gerais (Guimarães; Campos, 2008). Nesse sentido, foram elaboradas três diretrizes estratégicas: (i) reorganizar o setor público estadual; (ii) promover, de forma inovadora, o desenvolvimento econômico; (iii) recuperar o vigor político abalado pela crise fiscal (VILHENA, 2005).

A primeira geração desse Choque de Gestão é marcada por dois pontos fundamentais para a implantação do modelo de gestão pública para resultados, a saber: o 
gerenciamento intensivo dos projetos estruturadores e a contratualização de resultados.

No período, foi determinado um portfólio de 30 projetos estruturadores, que representavam as ações prioritárias do governo, submetidos à Gestão Estratégica de Recursos e Ações do Estado (Geraes), que adquiriu a função de escritório de projetos do governo. Adquirindo a função de escritório de projetos, o Geraes apresentou como principal atribuição o monitoramento intensivo da carteira recém-criada, ou seja, seria responsável por gerenciar os projetos de forma diferenciada, estabelecendo os planos, as metas e acompanhando o desempenho em relação ao planejado (BorGEs, 2008).

O instrumento de acompanhamento e solicitação de cotas orçamentárias dos projetos estruturadores é o status report, um dos documentos do projeto em que constam prazos, marcos e orçamento. É atualizado mensalmente em reuniões de acompanhamento coordenadas pelo Geraes, gerente, equipe e demais partes do projeto, nas quais há a atualização do cronograma do projeto, bem como o monitoramento de sua progressão (BORGES, 2008).

A adoção da contratualização de resultados foi promovida pela Superintendência Central de Modernização Institucional (Sumin). "O Acordo é um instrumento de pactuação de resultados, que se dá mediante a negociação entre dirigentes dos órgãos e entidades do Poder Executivo, bem como entre gerentes das unidades administrativas e autoridades que sobre eles tenham poder hierárquico ou de supervisão" (CARneiro; Barbosa, 2007, p. 2). Essa ferramenta gerencial celebra um "contrato" que representa um compromisso (negociado entre as partes) que regula as relações (via de regra) entre o núcleo estratégico (formulador de políticas) e as entidades descentralizadas (executoras) (Duarte; Lemos; Marini; Martins, 2006). O acompanhamento intensivo dos projetos considerados estratégicos, assim como os procedimentos de contratualização e de avaliação de desempenho do acordo de resultados foram os pilares da construção da gestão por resultados mineira.

O chamado Choque de Gestão de segunda geração tem suas bases expostas no Plano Mineiro de Desenvolvimento Integrado 2007-2023 (PMDI) e na estratégia do EpR. O Plano buscou estabelecer resultados finalísticos para 11 áreas de resultado - "áreas focais" de concentração dos esforços e recursos, visando a transformações e melhorias desejadas. Assim, cada área de resultados foi alvo da intervenção de um grupo de projetos estruturadores, reunidos em função de sua sinergia, e monitorados por um grupo de indicadores finalísticos (Minas Gerais, Pmdi, 2007). Nesse sentido, a reforma da segunda geração de políticas deixaria de se concentrar somente nos órgãos internos da administração pública e passaria a se preocupar em medir os benefícios e malefícios alcançados pelas políticas governamentais.

Qual foi a evolução que mostrou a necessidade da criação de mais uma unidade chamada Estado para Resultados? O que a gente observa é que a execução de projetos por si só e a superação de obstáculos que constam da agenda, não induziam a busca de resultados entendidos como ganhos sociais palpáveis. [...] Quando falamos em pactuar resultados, falamos em resultados expressos, quantificados, traduzidos em metas e que estejam atribuídos a diferentes unidades que integram a administração estadual. (Entrevistado C) 
Os entrevistados foram unânimes em afirmar a relação desproporcional entre a quantidade de informação gerada pelo Geraes e a capacidade do executivo principal de filtrá-la, ou seja, toda a informação gerada sobre os projetos não era assimilada satisfatoriamente pelos tomadores de decisão. A partir dessa demanda, foi desenvolvida a unidade de gestão estratégica no EpR, cujo objetivo é "filtrar" questões principais dos projetos estruturadores e transmiti-las ao executivo principal.

No processo de desenvolvimento e implementação desse filtro de informações, foram estabelecidas reuniões executivas chamadas de Comitês de Resultados, cujo objetivo era definir um plano de ação estratégico capaz de auxiliar no alcance dos objetivos perseguidos, bem como deliberar planos de intervenção (Entrevistado A). No início do programa, as reuniões seriam uma forma de apresentar os marcos e indicadores das áreas de resultado, bem como de atualizar as ações, riscos e dificuldades, em cada área de resultado.

Outro instrumento adotado foi o plano de ação, cujo objetivo é filtrar problemas, riscos, dificuldades e oportunidades estratégicas das áreas de resultado (originados, ou não, das reuniões de comitês) e organizá-los em um sistema de tecnologia da informação. Entende-se por plano de ação o instrumento pelo qual ações corretivas e preventivas de questões envolvendo os projetos estruturadores são elaboradas, documentadas e monitoradas até sua finalização. Por meio dele, são atribuídas responsabilidades e determinadas as circunstâncias em que o trabalho deverá ser realizado.

Além das reuniões de comitês e planos de ação, havia ainda a necessidade de um processo de "alinhamento" dentro da gestão estratégica. Denomina-se alinhamento a tarefa de assegurar sinergias entre equipes, processos, unidades de negócio e parceiros externos, cujo propósito, segundo Kaplan e Norton (2006), é assegurar que a estratégia, como instrumento de comunicação e de gestão, chegue aos níveis da organização e seja compartilhada (KAPLAN; Norton, 2006).

Assim, a unidade de gestão estratégica dedica-se principalmente às atividades relativas a comitês de resultados, planos de ação, apoio a gestão dos projetos estruturadores, associados e áreas estratégicas. Destaca-se que esta foi considerada a unidade com as ações mais desenvolvidas do programa, principalmente porque contém a realização dos comitês (Entrevistado A).

O comitê propriamente dito é para que o vice-governador tenha uma informação e gere uma tomada de decisão, uma colagem da estratégia, ou seja, fazer que coisas que não estão caminhando caminhem. [...] (Entrevistado A)

Inicialmente, os comitês eram realizados somente para as áreas de resultados descritas no PMDI 2007-2023. A primeira "rodada" de comitês apresentou o que foi planejado para o governo, até para que os interlocutores se tornassem familiares com a lógica de indicadores finalísticos (Entrevistado C). No entanto, não havia um modelo para a apresentação, e não se sabia ao certo o que retratar na apresentação (Entrevistado A).

A rodada seguinte concentrou-se nas entregas estratégicas e em resultados mais importantes, focando algumas áreas de resultado em especial. A Tabela 1 apresenta o número de realização de comitês, desde o ano de 2007 até outubro de 2009. 
Tabela 1: Número de reuniões de comitê por áreas de resultados

\begin{tabular}{|c|c|c|c|}
\hline Área de Resultados & 2007 & 2008 & $2009^{*}$ \\
\hline Defesa Social & 4 & 11 & 5 \\
\hline $\begin{array}{l}\text { Desenvolvimento do Norte de Minas, Jequitinhonha, Mucuri e } \\
\text { Rio Doce }\end{array}$ & 1 & 2 & 2 \\
\hline Educaçâo de Qualidade & 2 & 3 & 1 \\
\hline Inovaçâo, Tecnologia e Qualidade & 1 & 4 & 2 \\
\hline Investimento e Valor Agregado de Produçào & 3 & 8 & 3 \\
\hline Logística de Integraçâo e Desenyolvimento & 1 & 3 & 2 \\
\hline Protagonismo Juvenil & 1 & 12 & 13 \\
\hline Qualidade Ambiental & 1 & 4 & 1 \\
\hline Qualidade e Inovaçào em Gestâo Pública & 0 & 5 & 9 \\
\hline Qualidade Fiscal ${ }^{* *}$ & 9 & Q & 0 \\
\hline Rede de Cidades e Serviços & 3 & 7 & 13 \\
\hline Reduçào da Pobreza e Inclusâo Produtiva & 2 & 8 & 2 \\
\hline Vida Saudâvel & 1 & 2 & 1 \\
\hline Total & 20 & 69 & 54 \\
\hline
\end{tabular}

Fonte: Programa Estado para Resultados.

* Número de reuniões de comitê até outubro de 2009.

** A área de resultado Qualidade Fiscal não possui reuniões de comitê.

Nota-se, a partir da tabela, diferenças expressivas entre 2007 e 2008. Enquanto, no primeiro ano, ocorreu uma distribuição mais equilibrada de comitês por área de resultado, em 2008, algumas áreas de resultados se destacaram por apresentar um número muito maior de reuniões, diferenciação presente também em 2009. A aparente diferença entre o número de comitês de uma área de resultado e outra pode ser entendida como uma focalização maior das reuniões para os projetos (reunião de pequeno comitê) ou áreas de resultado com maiores problemas, ou como uma priorização de frentes do governo.

O pequeno comitê tornou-se viável quando o formato único de comitê por áreas de resultado demonstrou-se incapaz de abordar pontos que exigem mais discussão e possuem mais detalhes. Seu formato é mais restrito, com uma abordagem por projeto, um público menor e tempo reduzido. Como argumenta o Entrevistado C, o pequeno comitê foi uma evolução que proporcionou maior foco para as reuniões e ajustou a necessidade de menor quorum.

Alguns projetos, até pela sua complexidade, pelo nível de dificuldade, justificavam reuniões mais específicas e com um público menor, pois nessas reuniões menores você pode tratar do assunto de cada projeto de maneira mais extensa, até porque, se você chama mais pessoas para plateia da reunião, você inibe a participação de todos. [...] (Entrevistado C)

A unidade de indicadores, diferentemente da gestão estratégica, possui como atributos a pesquisa, avaliação e apuração dos indicadores finalísticos, bem como a 
ponderação sobre a aderência dos indicadores à estratégia do estado. Como sustenta Januzzi (2002), para seu emprego na pesquisa acadêmica ou na formulação e avaliação de políticas públicas, o indicador deve gozar de uma série de propriedades como relevância, validade, confiabilidade, cobertura, especificidade, historicidade, atualização etc. Assim, após a primeira avaliação dos indicadores estabelecidos no PMDI, uma série de questionamentos a respeito do cumprimento das propriedades, como as citadas por Januzzi (2002), surgiu.

No PMDI, os 106 indicadores finalísticos apresentavam um perfil de maturidade consideravelmente diferenciado: indicadores completos, ou seja, que possuíam metas para 2007 e 2011; indicadores com metas apenas para um dos dois períodos; indicadores somente com valor de referência; e indicadores sem nenhum dado apurado. Tal disposição oferece uma falta de uniformidade dos indicadores planejados e decorreria em dificuldades para sua avaliação subsequente. Observa-se que, embora a maior parte dos indicadores do PMDI tenha permanecido, um número considerável de indicadores não foi avaliado e proxies foram desenvolvidas alternativas similares para os indicadores originalmente propostos. Por exemplo, o indicador da área de resultados, inovação, tecnologia e qualidade, "dispêndio em P\&D como percentual do PIB”, foi avaliado pela proxy "recurso do tesouro empenhado pela Fapemig como percentual do PIB".

Para a pactuação em 2008, o número de indicadores passou para 101. Foram excluídos aqueles cuja apuração não era possível e incorporados novos indicadores. O quadro de 2009 apresentou mudanças menos significativas que o de 2008 e foi inserido no Caderno de Indicadores do Estado, que organiza e problematiza o conjunto de indicadores por meio de itens como fonte, periodicidade, limites e dados estatísticos. Tal caderno se destaca como importante fonte de registro.

Outra questão citada pelos entrevistados diz respeito à dificuldade em se estabelecer indicadores de resultado e contar com o apoio daqueles que estão sendo cobrados pelas suas metas, como os dirigentes das secretarias de estado e as



Indicadores avaliados segundo o PMDI

Indicadores avaliados por proxy PMDI

Indicadores nào avaliados

Fonte: Programa Estado para Resultados.

Figura 1: Diagnóstico da Avaliação dos Indicadores Finalísticos dos Acordos de Resultado 2007 - MINAS GERAIS, 2008. 
equipes dos projetos estruturadores e associados. Como comenta o Entrevistado C:

Quase ninguém gosta de ter meta estabelecida para ele e ser acompanhado, porque significa tirar um pouco as pessoas da zona de conforto. E a função do EpR é tirar da zona de conforto, tirar da inércia, vencer os pontos onde o estado não tem feito o melhor de si, não tem produzido aquilo que é desejável. (Entrevistado C)

Além da própria natureza dos indicadores em estipular metas e cobrar resultados, não menos importante, está o trade-off de trabalhar com indicadores: não importa se eles são abrangentes ou defasados, sempre serão criticados. Nas palavras do Entrevistado B:

Nunca vai existir uma estrutura perfeita de indicadores [...] porque nenhum indicador atende a tudo que você precisa, quanto mais gerais e mais abrangentes, mais defasados eles são. Aí você tem um trade-off entre defasagem e abrangência que é uma coisa muito difícil. (Entrevistado B)

Parte do comentário é comprovado por Januzzi (2002), que, apesar de admitir que a disponibilidade de um sistema de indicadores certamente potencializa as chances de sucesso do processo de formulação e implementação de políticas públicas (JANUZZI, 2002), argumenta que na prática nem sempre o indicador de maior validade é o mais confiável, nem sempre o mais sensível possui a periodicidade requerida, e assim por diante. Ainda que o indicador reúna muitas qualidades, o governo não é dispensado da tarefa de avaliar o grau de aderência dos indicadores disponíveis às propriedades necessárias.

Além disso, o trabalho de estipular indicadores governamentais dificilmente será neutro e estático, uma vez que a implementação das políticas está sujeita ao papel desempenhado pelos agentes encarregados de colocá-las em ação e avaliá-las, impedindo a acomodação de interesses; e o contexto social propõe novos desafios



para o planejamento, necessitando atualizar as medidas de desempenho.

Para completar a lógica entre as unidades dedicadas à estratégia e à medição de resultados, foi criada a unidade responsável pelos empreendedores públicos.

A figura do empreendedor público surgiu para fornecer um apoio técnico e temporário aos pontos críticos das 
secretarias de estado, dos projetos estruturadores e associados e das áreas estratégicas. A ideia do empreendedor está relacionada, portanto, a uma "força tarefa" que propõe o cumprimento de atividades para o alcance de resultados; uma vez alcançados os resultados, o empreendedor deverá ser realocado ou deixar o cargo. Assim como comenta o Entrevistado C, o empreendedor não supre a administração pública de recursos humanos para as secretarias.

Os 90 cargos de provimento em comissão, de recrutamento amplo para os empreendedores públicos, foram criados a partir da Lei Delegada no 174, de 26 de janeiro de 2007, sendo 45 empreendedores I e igual número para empreendedor II. Os cargos são destinados aos encargos temporários do EpR, extinguindo-se em 31 de janeiro de 2011, juntamente com o programa.

Tal iniciativa foi inspirada na experiência chilena com o objetivo de buscar a profissionalização da alta direção dos serviços do Estado. A ideia proveniente do governo federal do Chile propõe uma modernização da gestão de recursos humanos, tanto em nível gerencial (Alta Direção Pública) quanto nas carreiras funcionais do serviço público, contemplando três pilares: 1) Sistema de Alta Direção Pública (SADP); 2) Desenvolvimento de pessoal e carreira funcional; e 3) Criação da Direção Nacional do Serviço Civil (DNSC) (BAU AEdo, 2005).

Para prover as vagas dos cargos de alta direção, o ingresso ocorre por meio da Direção Nacional do Serviço Civil (DNSC) ${ }^{1}$ e do Conselho de Alta Direção Pública ${ }^{2}$, que convocam um processo de seleção pública; os ministros do governo devem propor os perfis profissionais para os cargos e o conselho deve propor ao presidente da República uma lista de três a cinco candidatos selecionados.
Em Minas Gerais, a partir do Decreto $\mathrm{n}^{\circ} 44.490$, de 2007, instituiu-se o Comitê para Pré-Qualificação dos Empreendedores Públicos (Copep), órgão colegiado composto por cinco membros (coordenador executivo e adjunto do programa e três profissionais com notória experiência em administração pública indicados pelo vice-governador do estado), cuja ideia principal é "dividir responsabilidades e discutir sobre o processo de seleção, alocação e avaliação de empreendedores públicos" (Entrevistado B).

O modelo de gestão dos empreendedores públicos apresenta três subsistemas: recrutamento e seleção, desenvolvimento e aplicação de pessoas e remuneração (Bernardi \& Guimarães, 2008). O primeiro diz respeito ao processo de préqualificação dos empreendedores, o segundo aos programas de desenvolvimento e, por fim, o último sinaliza o monitoramento de seu desempenho, com a previsão de pagamento de parcela remuneratória variável.

As seis etapas para o processo de préqualificação do empreendedor são: 1) elaboração do perfil específico do empreendedor pela entidade solicitante e coordenador do EpR; 2) análise curricular e entrevistas preliminares; 3) aplicação dos métodos de avaliação como teste de personalidade, aptidão gerencial e entrevistas individuais por competência realizados por consultoria especializada; 4) deliberação do Copep; 5) devolutiva oferecida ao solicitante do perfil; e 6) sugestão do nome do candidato pré-qualificado indicado encaminhada ao governador para nomeação.

Os programas de desenvolvimento ocorrem mensalmente, com apoio de consultoria especializada, e englobam o desenvolvimento do grupo de empreendedores públicos e não o desenvolvimento 
pessoal do ocupante do cargo, focando as experiências do trabalho como empreendedor (Bernardi; Guimarães, 2008).

[...] a proposta desse trabalho de desenvolvimento não é uma proposta de trabalho individual de cada empreendedor, a ideia é desenvolver o grupo de empreendedores, é criar laços, é criar identidade entre eles, é fazer uma rede de pessoas que estão trabalhando com desafios, é desenvolver um pouco essa "força tarefa". (Entrevistado D)

O monitoramento e avaliação dos empreendedores públicos são realizados a partir do plano de trabalho do empreendedor (Entrevistado B), sendo este o principal instrumento de alinhamento do empreendedor público aos resultados e metas constantes da estratégia de governo (Bernardi; Guimarães, 2008).

A partir da construção teórica dos dois modelos, o chileno e o mineiro, é possível notar o número de diferenças consideráveis entre ambos (Quadro 1). Segundo o Entrevistado D, "o modelo deles (Chile) é muito mais complexo, amplo, até mais burocrático - é muito mais parecido com um concurso público que o nosso, e precisava ser adaptado" (Entrevistado D).

Quanto aos 90 cargos, pensou-se, primeiramente, em uma atuação maior dos empreendedores como gerentes de projetos (Entrevistado D), já que os gerentes e gerentes-adjuntos eram da alta administração e não se dedicavam exclusivamente

\section{Quadro 1: Principais diferenças entre o Sistema de Alta Dirección Pública e os Empreendedores Públicos}

\begin{tabular}{|c|c|c|}
\hline Características & $\begin{array}{l}\text { Sistema de Alta Dirección Pública } \\
\text { Chile }\end{array}$ & $\begin{array}{l}\text { Empreendedores Püblicos } \\
\text { Minas Gerais }\end{array}$ \\
\hline $\begin{array}{l}\text { Tempo de } \\
\text { duracáo }\end{array}$ & Possibilidade de renovaçăo. & Prazo de duraçào. \\
\hline Processó Seletivo & $\begin{array}{l}\text { Participaçào ampliada. com publicaçào } \\
\text { de edital. }\end{array}$ & $\begin{array}{l}\text { Participaçào restrita, com base somente na } \\
\text { rede de relacionamentos propria. }\end{array}$ \\
\hline Regulamentaçao & Processo seletivo regulamentado em lei. & $\begin{array}{l}\text { Processo seletivo definido por lei e } \\
\text { regulamentado } \mathrm{cm} \text { decreto. }\end{array}$ \\
\hline Orgào gestor & $\begin{array}{l}\text { Direçâo Nacional do Servico Civil } \\
\text { (DNSC). }\end{array}$ & Unidade de empreendedores. \\
\hline Conselho & $\begin{array}{l}\text { Conselho de Alta Direção Pública: } 4 \text { membros } \\
\text { nomeados pelo presidente e ratificação } \\
\text { por } 4 / 7 \text { dos senadores do Chile. }\end{array}$ & $\begin{array}{l}\text { Copep: } 5 \text { membros, sendo eles: o } \\
\text { coordenador executivo e adjunto do EpR. } \\
\text { mais trés membros nomeados pelo vice- } \\
\text { governador. }\end{array}$ \\
\hline Avaliaçōes & $\begin{array}{l}\text { Acordos de desempenho, com metas } \\
\text { trimestrais. }\end{array}$ & Planos de trabalhos, com metas anuais. \\
\hline $\begin{array}{l}\text { Programas de } \\
\text { desenvolvimento }\end{array}$ & Processos de certificaçào e pós-graduação. & $\begin{array}{l}\text { Reuniöes mensaís com base em experièncias } \\
\text { vivenciadas pelos empreendedores. }\end{array}$ \\
\hline Remuneraça & $\begin{array}{l}\text { Remuneraçao fixal somada a parcela } \\
\text { variável, com base no cumprimento das } \\
\text { metas dos acordos de desempenho. }\end{array}$ & $\begin{array}{l}\text { Remuneraçào fixa somada a parcela variável } \\
\text { com base no cumprimento das metas dos } \\
\text { planos de trabalho e critérios de desempenho } \\
\text { definidos pelo Copep }\end{array}$ \\
\hline
\end{tabular}

Fonte: Elaboração própria. 




Fonte: Programa Estado para Resultados.

Nota: Situação em 10/06/2009.

Figura 2: Distribuição dos Empreendedores Públicos por Função Minas Gerais 2009.

aos resultados dos projetos. Atualmente, entretanto, a distribuição dos empreendedores distancia-se da hipótese original (Figura 2).

Além disso, a proposta inicial para a remuneração variável dos empreendedores era bastante diferenciada da instituída. Ao contrário de até uma remuneração por ano, a primeira proposta era instituir uma remuneração fixa menor que a atual e uma remuneração variável de até cinco salários por ano, para que os empreendedores realmente se mobilizassem a fim de alcançar os resultados pactuados (Entrevistado D).

Entretanto, a proposta não prevaleceu devido à cultura política mineira (Entrevistado F). Ou seja, as propostas iniciais recomendavam mudanças expressivas no estado e, caso fossem implantadas, poderiam encontrar uma resistência maior do que a ocorrida nos órgãos de alocação dos empreendedores.
Temos que conseguir enxergar a nossa possibilidade de inovação vis-àvis o nosso direito a nossa cultura política, porque nós estaríamos sujeitos a muita crítica. Quer dizer, já foi uma inovação, já teve resistência, imagina se nós tivéssemos uma remuneração variável maior frente a todos os servidores...então, a isonomia nos segurou. (Entrevistado F)

A partir do momento em que a lei estava publicada, surgiram as dificuldades para a inserção do empreendedor público nas secretarias, áreas estratégicas e projetos. Os grandes desafios iniciais, nesse sentido, foram, primeiro, trazer pessoas e definir perfis (Entrevistado A) e, segundo, inserir o empreendedor público na ponta (Entrevistado B).

Nota-se também que ocorreu resistência quanto "a própria aceitação do modelo" 
dos empreendedores (Entrevistado D). Destaca-se entre os opositores parte dos servidores, de secretarias e outros órgãos do estado, descontentes principalmente com a questão salarial, já que muitos empreendedores recém-contratados possuíam remuneração maior que servidores públicos que trabalhavam na área há mais tempo.

Outro grande desafio inicial foi o problema da "dupla chefia" (Entrevistado B), ou seja, o vínculo formal do empreendedor está no Estado para Resultados, porém, alguns lidam com a hierarquia interna da secretaria, onde trabalham e acabam absorvendo novas tarefas. Um dos problemas advindos dessa "dupla chefia" é o prejuízo do próprio plano de trabalho dos empreendedores, pois eles se desviam das atividades que foram contratados para fazer.

Talvez o empreendedor esteja em uma secretaria e o chefe dele é um secretário de estado, mas ele tem um vínculo formal com o EpR. Então ele tem uma dupla chefia que é uma coisa completamente nova e não é fácil. Mas a escolha é essa mesmo, a gente acha que é a única forma do empreendedor não ser absorvido pela estrutura. (Entrevistado B)

Por fim, com relação à avaliação e ao monitoramento dos empreendedores, surgiu a dificuldade de desenvolver e avaliar (plano de trabalho) o grupo de empreendedores, considerando a heterogeneidade dos perfis, as diferenças culturais nos órgãos de exercício, a diversidade das tarefas desempenhadas por eles e dos resultados que precisam ser entregues.

Como principais desafios da unidade de empreendedores públicos, foram citados a gestão estratégica do grupo de empreendedores, o alargamento do processo de seleção e, por fim, o processo de avaliação e desenvolvimento do grupo - que também foram citados como dificuldades iniciais.

Dessa forma, a criação do EpR na administração pública mineira deu-se por dois motivos principais: o primeiro diz respeito ao próprio gerenciamento das mudanças da estratégia do governo demonstrada no PMDI 2007-2023 e sua

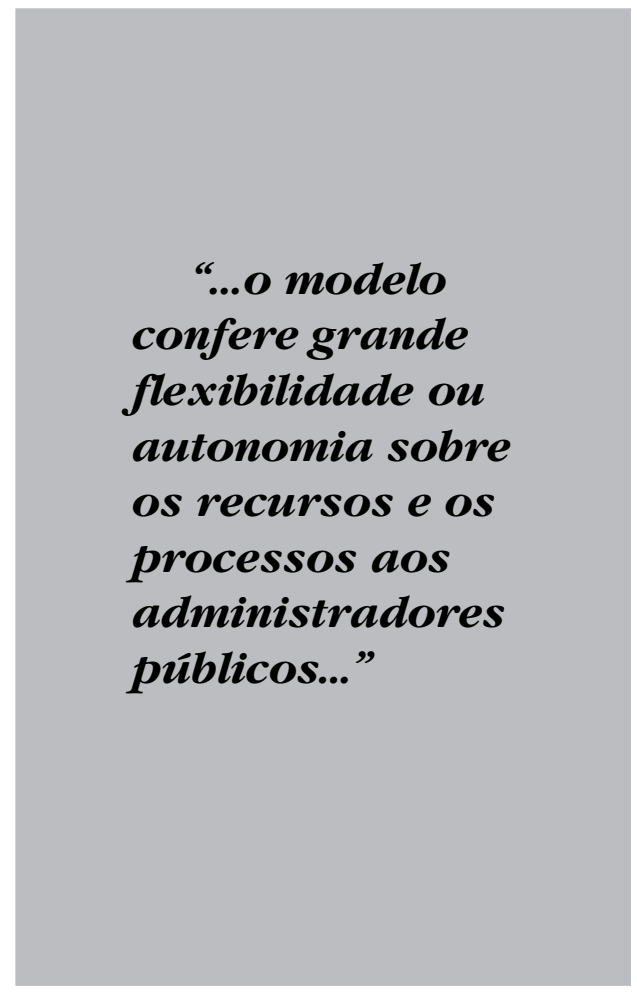

preocupação em propor indicadores e traduzi-los em metas; e o segundo aborda o gerenciamento estratégico das ações de governo, transformado em comitês de resultado, plano de ação e na busca pelo aprimoramento do alinhamento estratégico. A questão relativa à mão de obra do programa foi completada com a lógica dos empreendedores públicos, entendidos 
como uma força-tarefa para as ações consideradas importantes no estado.

Assim, com vistas a proceder à gestão estratégica das áreas de resultado, bem como acompanhar os indicadores do PMDI por meio da alocação de empreendedores públicos, a criação do programa ocorreu com base no art. $8^{\circ}$ da Lei Delegada no 112 , de 25 de janeiro de 2007. Em alusão à norma, destaca-se que as atividades listadas inicialmente para o EpR resumem-se na "atuação de frentes que viabilizem a estratégia de governo" (Entrevistado A).

Considerando a função de coordenação do programa e sua relação com a alta gerência do estado, sua vinculação à estrutura de governo foi regularizada pelo Decreto $n^{\circ} 44.447$, de 26 de janeiro de 2007, que classificou o EpR como um staff direto do vice-governador do estado.

Outro ponto importante nessa discussão considera que a vinculação a um ente político - cargo de vice-governador transforma, portanto, o EpR em uma unidade transitória na administração pública mineira, já que não é possível afirmar que o mesmo vice-governador continuará no cargo após quatro anos de mandato. A proposta foi, então, transformar o programa em uma estrutura provisória da administração pública, com início em 2007 e fim em janeiro de $2011^{3}$.

Por fim, como comenta o Entrevistado B, a implementação do Estado para Resultados, em suas três frentes de atuação, contribuiu para que o processo de tomada de decisões fosse mais efetivo, com decisões mais seguras:

Hoje, a alta gerência do governo (governador, vice-governador, secretários) com o fluxo de fazer comitês, ter empreendedor, medir indicadores, [...] consegue reunir um conjunto de informação muito bom para que aquela decisão seja tomada. As decisões tendem a ser mais acertadas e mais seguras. (Entrevistado B)

\section{Considerações finais}

Quanto ao modelo de gestão por resultados, destaca-se o direcionamento dos organismos públicos para atuar sobre todos os aspectos que afetam ou modelam os resultados da organização, em busca da criação de valor público. O modelo supõe essencialmente que os efeitos das intervenções públicas, em substituição à coordenação por procedimentos, são o que de fato importa ao cidadão, que é a mudança real nas condições de vida.

Assim, a gestão pública por resultados pode ser entendida como um ciclo que se inicia com o planejamento dos efeitos almejados, a partir da operacionalização dos objetivos de governo; que prescreve o monitoramento e a avaliação do desempenho da organização ou da política pública a partir do alcance desses efeitos; e que retroalimenta o sistema de gestão, propiciando o feedback decorrente dessa avaliação. Ademais, o modelo confere grande flexibilidade ou autonomia sobre os recursos e os processos aos administradores públicos, que estabelecem sanções positivas e negativas frente ao desempenho alcançado.

A gestão pública por resultados foi introduzida em Minas Gerais em um contexto de reforma administrativa, denominada Choque de Gestão, possuindo como bases o PMDI 2003-2020 e o escritório central de projetos (Geraes), e operacionalizada, em princípio, pelos acordos de resultados, PMDI 2007-2023 e Programa Estado para Resultados.

Seguindo os princípios da gestão por resultados, a contratualização de resultados 
introduziu mecanismos de incentivos e sansão frente ao desempenho alcançado. Para reforçar o modelo de gestão por resultados, houve a introdução de objetivos estratégicos e indicadores finalísticos no PMDI 2007-2023. Submetido à aprovação da Assembleia Legislativa, o plano constitui-se um importante marco do modelo, na medida em que disponibiliza o conhecimento das metas de governo.

Por fim, o EpR complementa a cadeia da gestão por resultados mineira. Suas funções podem ser entendidas como um processo que se inicia com o estabelecimento dos resultados desejados e prossegue na busca por esses resultados, por meio do trabalho de empreendedores públicos alocados em áreas críticas, no monitoramento da atuação por meio dos comitês de resultado e na avaliação do desempenho das políticas públicas a partir do quadro de indicadores finalísticos. Assim, o EpR, por intermédio de suas três unidades essenciais, busca permitir que a estratégia do governo seja, de fato, implementada.

Tendo em vista tais proposições, o modelo mineiro de gestão pública por resultados se apresenta como coerente por abordar as três dimensões descritas por Serra (2008): conceitual, na medida em que os resultados almejados são traduzidos em objetivos estratégicos e indicadores finalísticos; cultural, quanto à vinculação dos dirigentes aos resultados perseguidos; e operacional, na aplicação de sanções, positivas e negativas, a partir da avaliação do alcance dos resultados.

No entanto, considerando as entrevistas analisadas e a trajetória em construção pelo EpR, salientam-se dificuldades e limitações inerentes ao modelo de gestão pública por resultados, principalmente o feedback das avaliações realizadas, a partir da apuração dos indicadores finalísticos, capazes de retroalimentar o sistema de gestão e propiciar, assim, ações corretivas.

Nota-se, portanto, na visão dos entrevistados, a contribuição do modelo incremental do Programa Estado para Resultados na busca por uma melhor consecução da estratégia do governo. Nesse sentido, por meio das análises realizadas, atenta-se para algumas boas práticas deixadas pelo programa, como: filtrar informações estratégicas e transportá-las ao executivo principal; selecionar pessoas para a administração pública de forma impessoal; desenvolver o quadro de indicadores finalísticos, buscando torná-lo mais relevante e confiável.

(Artigo recebido em março de 2012. Versão final em dezembro de 2012).

\section{Notas}

${ }^{1}$ A Direção Nacional do Serviço Civil (DNSC) é um serviço descentralizado do Ministério da Fazenda, que coordena, supervisiona e aperfeiçoa os recursos humanos do Estado. Sua missão é de "institucionalizar uma nova política de gestão e desenvolvimento de pessoal da administração pública, baseada no mérito e na idoneidade, que contribua para melhorar a eficácia e a eficiência de serviços em prol da cidadania." 
${ }^{2}$ O Conselho de Alta Direção Pública possui como funções principais a condução e regulação do processo de seleção de candidatos a cargos do sistema de alta direção. Os integrantes do conselho são quatro membros nomeados pelo presidente e ratificados pelo Senado, por 4/7 dos senadores em exercício.

${ }^{3}$ Dessa maneira, todos os cargos associados à estrutura do programa também seriam provisórios, incluindo os cargos de empreendedores públicos, com fim em janeiro de 2011.

\section{Referências bibliográficas}

Anastasia, A. A. J. Apresentação. In: ViLhenA, R. et al. (Orgs.). O choque de gestão em Minas Gerais: políticas da gestão pública para o desenvolvimento. Belo Horizonte: UFMG, 2006. Bandeira-de-melo, R.; Cunha, C. J. C. de A. Grounded theory. In: Godoi, C. K.; BanDEIRA-DE-MELO, R.; Silva, A. B. Pesquisa qualitativa em estudos organizacionais: paradigmas, estratégias e métodos. São Paulo: Saraiva, 2006.

. Operacionalizando o Método da Grounded Theory nas Pesquisas em Estratégia: técnicas e procedimentos de análise com apoio do software Atlas/Ti. In: Encontro da Associação Nacional de Pós-graduação e Pesquisa em Administração, 21, 2003, Rio de Janeiro. Anais... Rio de Janeiro: EnAnpad, 2003.

Bau Aedo, C. Experiencias Exitosas en la Profesionalización de la Función Pública en América Latina - El caso de Chile. In: Foro IberoAmericano: Revitalización de la Administración Pública. Estrategias para la Implantación de la Carta Iberoamericana de la Función Pública. Ciudad de México, México, mayo de 2005.

Bernardi, M.; Guimarães, T. B. Empreendedores públicos: uma experiência de gestão estratégica de pessoas na administração pública do Governo do Estado de Minas Gerais. In: XIII Congreso Internacional del Clad Sobre la Reforma del Estado y de la Administración Pública, 13, 2008, Buenos Aires. Anais... Buenos Aires: CLAD, 2008.

Borges, T. B. A Construção do Alinhamento Estratégico no Estado de Minas Gerais. 2008. Monografia (Graduação em Administração Pública). Fundação João Pinheiro, Escola de Governo Professor Paulo Neves de Carvalho, Belo Horizonte.

Carneiro, R.; Barbosa, L. O. S. Acordo de Resultados: Análise da Experiência do Governo Mineiro. In: Encontro da Associação Nacional de Pós-graduação e Pesquisa em Administração, 31, 2007, Rio de Janeiro. Anais... Rio de Janeiro: EnAnpad, 2007.

CORrÊA, I. M. Planejamento estratégico e gestão pública por resultados no processo de reforma administrativa do Estado de Minas Gerais. Revista de Administração Pública, v. 41, n. 3, pp. 487-504, mai./jun. 2007.

Duarte, K.; Lemos, C.; Marini, C.; Martins, H. F. Acordo de Resultados. In: Vilhena, R. et al. (Orgs.). O choque de gestão em Minas Gerais: políticas da gestão pública para o desenvolvimento. Belo Horizonte: UFMG, 2006. Cap. 6, p. 95- 127. 
Guimarães, T. B.; Campos, E. S. A. Gestão da estratégia no Governo do Estado de Minas Gerais: em busca da harmonia entre a ação e os resultados. In: XIII CONGRESSO INTERNAcional del Clad sobre la Reforma del Estado y de la Administración Pública, 13, 2008, Buenos Aires. Anais... Buenos Aires: CLAD, 2008.

Guimarães, T. B.; Almeida, B. de. O. Duplo Planejamento. Vilhena, R. et al. (Orgs.). O choque de gestão em Minas Gerais: políticas da gestão pública para o desenvolvimento. Belo Horizonte: UFMG, 2006. Cap. 2, p. 43-54.

Hair JR., J.; Babin, B.; Money, A.; SAMOUel, P. Fundamentos de métodos de pesquisa em administração. Porto Alegre: Bookman, 2005.

Januzzi, P. de M. Indicadores Sociais na Formulação e Avaliação de Políticas Públicas. Revista Brasileira de Administração Pública, v. 36, pp. 51-72, jan./ fev. 2002.

. Indicadores para diagnóstico, monitoramento e avaliação de programas sociais no Brasil. Revista do Serviço Público, n. 56, v. 2, pp. 137-160, abr./jun. 2005.

Kaplan, R.; Norton, D. P. Alignment: using the balanced scorecard to create corporate synergies. Cambridge: Harvard Bussiness School press, 2006.

Minas Gerais. Secretaria de Planejamento e Gestão. Plano Mineiro de Desenvolvimento Integrado 2007-2023. Belo Horizonte, 2007.

Moore, M. Creating Public Value: Strategic Management in Government. Cambridge: Harvard University Press, 1995.

Moynihan, D. P. Managing for Results in State Government: Evaluating a Decade of Reform. Public Administration Review, n. 1, v. 66, p. 77-89, jan./feb. 2006.

OcDe. Glossário dos Principais Termos da Avaliação e da Gestão Centrada nos Resultados. 2002. Recuperado em 07 setembro, 2009, de < http:/ / www.oecd.org/development/ peerreview sofdacmembers/17486415.pdf $>$.

Osborne, D.; Gaebler, T. Reinventando o governo; como o espírito empreendedor está transformando o setor público. Brasília: MH Comunicação, 1995.

SERRA, A. Modelo aberto de gestão para resultados no setor público. Natal: SEARH, 2008.

VilhenA, R. Rumo à Segunda Geração do Choque de Gestão. VILHENA, R. et al. (Orgs.). O choque de gestão em Minas Gerais: políticas da gestão pública para o desenvolvimento. Belo Horizonte: UFMG, 2006. Cap. 20, p. 351-356. 


\section{Resumo - Resumen - Abstract}

O modelo de gestão pública por resultados em Minas Gerais analisado à luz da experiência do Programa Estado para Resultados

Cinthia Helena O. Bechelaine, Mauro César da Silveira e Camila Barbosa Neves

O presente trabalho almeja investigar o processo de desenvolvimento da gestão por resultados em Minas Gerais, marca da segunda geração de políticas mineira intitulada Choque de Gestão. Em termos específicos, objetiva-se analisar o Programa Estado para Resultados (EpR), sua composição, processo de construção e estrutura de funcionamento. Como método de pesquisa, utilizou-se a grounded theory, traduzida por teoria fundamentada nos dados e apresentada como uma alternativa para pesquisas qualitativas sobre fenômenos organizacionais. Apresentase uma discussão teórica que visa a definir o conceito de gestão pública por resultados, cuja finalidade é a criação de valor público. As implicações dessa discussão são ilustradas e problematizadas em um estudo de caso do EpR, à luz de seus antecedentes. Por fim, conclui-se que o EpR constitui um modelo híbrido e particular da gestão por resultados mineira que visa, essencialmente, a consecução da estratégia de governo e o suporte aos processos de tomada de decisões no estado.

Palavras-chave: Gestão; público; resultados

El modelo de gestión pública por resultados en Minas Gerais analizado a la luz de la experiencia del programa 'Estado para Resultados' Cinthia Helena O. Bechelaine, Mauro César da Silveira y Camila Barbosa Neves

El presente estudio tiene como objetivo investigar el proceso de desarrollo de la gestión por resultados en Minas Gerais, marca de la segunda generación de la política titulada Choque de Gestão. Tiene el propósito de analizar la composición del Programa Estado para Resultados (EpR), su proceso de construcción y la estructura operativa. Como método de investigación, hemos utilizado la grounded theory, traducido por la teoria firmada en una base de dados y presentada (la teoria) como una alternativa a la investigación cualitativa sobre los fenómenos organizacionales. Se presenta una discusión teórica destinada a definir el concepto de gestión pública por resultados. Las implicaciones de este debate se ilustran y se problematizan en un estudio de caso del EpR, bajo la luz de sus antecedentes. Por último, la conclusión de que el EpR es un determinado modelo híbrido de gestión de Minas Gerais, que tiene como objetivo primordial el logro de la estrategia del gobierno y el apoyo de los procesos de toma de decisiones en el estado.

Palabras clave: Gestión; público; resultados

The model of the results-based management in Minas Gerais: analyzing the experience of the Estado para Resultados Program

Cinthia Helena O. Bechelaine, Mauro César da Silveira and Camila Barbosa Neves

This paper aims to investigate the process of development of the results-based management in Minas Gerais, label of the second policy generation entitled Management Shock. The main goal is to analyze the composition of the Estado para Resultados program (EpR), its construction process and operating structure behind the program. The research method used is the grounded theory. This paper presents a theoretical discussion aimed at defining the 
concept of the results-based management in the public sector. The implications of this discussion are illustrated and problematized in a case study of the EpR, based in its background stemming. Finally, the conclusion that the EpR is a particular hybrid model of Minas Gerais's management and that aims primarily achieving the government strategy and support the decisionmaking processes in the state.

Keywords: Management; public; results

Cinthia Helena de Oliveira Bechelaine

Mestranda em Administração pela Universidade Federal de Minas Gerais (UFMG) e bacharel em administração pública pela Fundação João Pinheiro. Analista de desenvolvimento do Banco de Desenvolvimento de Minas Gerais S/A (BDMG). Contato: cinthia.bechelaine@gmail.com

Mauro César da Silveira

Doutorando em administração pela Universidade Federal de Minas Gerais (UFMG), mestre em administração pela UFMG e bacharel em Direito pela Universidade Federal de Juiz de Fora (UFJF). Especialista em Políticas Públicas e Gestão Governamental do Governo do Estado de Minas Gerais. Contato: maurocsilveira@hotmail.com

Camila Barbosa Neves

Bacharel em administração pública. Especialista em Políticas Públicas e Gestão Governamental do Governo do Estado de Minas Gerais. Contato: camila.neves@planejamento.mg.gov.br 